\title{
The Importance of Water Quality and Haemodialysis Fluid Composition
}

\author{
Nicholas A. Hoenich ${ }^{a}$ Claudio Ronco ${ }^{b}$ Robert Levin ${ }^{c}$ \\ a School of Clinical Medical Sciences, University of Newcastle upon Tyne, Newcastle upon Tyne, UK; \\ ${ }^{b}$ Department of Nephrology, San Bortolo Hospital, Vicenza, Italy; ${ }^{c}$ Renal Research Institute, New York, N.Y., USA
}

\section{Key Words}

Dialysis fluid $\cdot$ Water contaminants $\cdot$ Haemodialysis

\begin{abstract}
Treatment of renal failure by haemodialysis uses dialysis fluid to facilitate the normalization of electrolyte and acid base abnormalities and the removal of low molecular weight uraemic compounds present in the plasma such as urea. The dialysis fluid is a continuously produced blend of treated tap water and a concentrated solution containing electrolytes, buffer, and glucose. The water used originates as drinking water but undergoes additional treatment. Recent surveys have indicated that the chemical and microbiological content of such water frequently fails to meet the requirements of established standards, and its bacterial content arising from the presence of a biofilm in the water distribution network or the hydraulic circuit of the dialysis machine is a contributory factor to the chronic inflammatory state in patients undergoing regular dialysis. The composition of the dialysis fluid plays an important role in the modulation of complications associated with end-stage renal disease, as well as those associated with the treatment itself. The avoidance of complications arising from water contaminants requires a constant and vigorous attention to wa-
\end{abstract}

ter quality, whilst with the composition of electrolytes and buffer there is a trend towards greater individualization to provide a high degree of treatment tolerance.

Copyright (C) 2006 S. Karger AG, Basel

\section{Introduction}

Haemodialysis is a simple diffusive process including the restoration of electrolyte and acid base balance, the removal of fluid and low molecular weight uraemic toxins. This is achieved by the use of an artificial kidney or a haemodialyser, containing a semi-permeable membrane in which there is contra-parallel flow of blood and dialysis fluid to facilitate the physical processes. The dialysis fluid consists of treated tap water mixed with an electrolyte concentrate that also contains a buffer and glucose.

Both the composition of the concentrate and the quality of water used in the preparation of the dialysis fluid play an important role in patient well-being. The purpose of this paper is to discuss these aspects of haemodialysis.

\section{KARGER}

Fax +41613061234 E-Mail karger@karger.ch www.karger.com 


\section{Water Quality in Haemodialysis}

Water used in the preparation of dialysis fluid or when dialyzers are reused originates as drinking water that meets the legal standards for drinking water quality. Patients with renal failure are exposed to higher volumes of water in their lifetime than the general population, and unlike in the normal population where the gut forms an effective barrier to contaminants in the water, the barrier for dialysis patients is in the form of a nonselective semipermeable membrane, providing a direct route for any contaminants into the bloodstream. As many of the permitted levels of contaminants in drinking water have the potential to cause problems in dialysis patients (table 1), contaminant levels in water used in the preparation of dialysis fluid are set at much lower levels than in drinking water (table 2).

Attainment of these levels necessitates that water used in the preparation of dialysis fluid undergoes additional treatment. The realization that additional treatment was needed first emerged in the late 1970s when a number of problems deriving from trace metal presence in the water

Table 1. Common symptoms during dialysis and water contaminants capable of causing them

\begin{tabular}{ll}
\hline Symptom & Water contaminant \\
\hline Anaemia & $\mathrm{Al}$, chloramine, nitrate, $\mathrm{Pb}, \mathrm{Cu}, \mathrm{Zn}, \mathrm{Si}$ \\
Bone disease & $\mathrm{Al}$, fluoride, $\mathrm{Si}$ \\
Hypertension & $\mathrm{Ca}, \mathrm{Mg}, \mathrm{Na}$ \\
Hypotension & bacteria, endotoxin, nitrate \\
Acidosis & low pH, sulphate \\
Muscle weakness & $\mathrm{Ca}, \mathrm{Mg}$ \\
Nausea/vomiting & bacteria, endotoxin, chloramine, low \\
& $\mathrm{pH}$, nitrate, sulphate, $\mathrm{Ca}, \mathrm{Mg}, \mathrm{Cu}, \mathrm{Zn}$ \\
Neurological disturbances & $\mathrm{Al}, \mathrm{Pb}, \mathrm{Ca}, \mathrm{Mg}$ \\
\hline
\end{tabular}

were described $[1,2]$. This subsequently led to the development of national and international standards for water used in the preparation of dialysis fluid defining the maximum permissible contaminant levels [3-5].

The use of additional water treatment has largely eliminated the historic problems arising from chemical contaminants, although sporadic episodes of contamination due to equipment failure or changes in procedure at the filtration plants of the water utilities continue to occur $[6,7]$.

Historically, the water treatment used was simple, utilizing particulate filtration, water softeners, and deionizers; however, water treatment plants in use today are considerably more complex with the exact nature of the plant being determined by the quality of the incoming or feed water and the volume of the treated or product water required (fig. 1).

Despite the existence of standards and a more complex treatment, a number of national and international surveys have highlighted shortcomings in attaining the contaminant levels specified in the standards [7-10]. There have also been suggestions that the levels set in the standards may not be stringent enough [11]. There may also be a problem obtaining trace metal-free concentrates for the preparation of the final dialysis solution in some areas of the world [12].

Drinking water contains varying levels of chlorine, added to disinfect the water. However, some water utilities prefer the use of chloramine as an alternative due to the unacceptable levels of trihalomethanes, carcinogenic compounds that can be produced from the interaction of chlorine with natural organics from vegetation.

Chlorine and chloramines are not removed by either reverse osmosis (RO) or deionization systems and can only be removed by the use of granulated activated carbons. These may be in the form of fluidized beds or impregnated filters. Removal is achieved via a combination of adsorption and chemical reaction which depend on a
Table 2. Comparison of contaminant limits for drinking water and water for haemodialysis

\begin{tabular}{llcl}
\hline Contaminant & Clinical effect & $\begin{array}{l}\text { Drinking water } \\
\mathrm{mg} / \mathrm{l}\end{array}$ & $\begin{array}{l}\text { Water for dialysis } \\
\mathrm{mg} / \mathrm{l}\end{array}$ \\
\hline Chlorine/chloramine & hemolysis & $<4$ & 0.1 total chlorine \\
Calcium & hard water syndrome & 250 & $2(0.8)$ \\
Nitrate/nitrite & nausea & 50 & $2(4)$ \\
Aluminium & dementia & 0.2 & $0.01(5)$ \\
\hline
\end{tabular}

Figures in parentheses indicate percentage of drinking water limit. 
Fig. 1. A typical water treatment plant used to provide high quality water suitable for haemodialysis. (Photograph by courtesy of Lars-Goran Nilsson and Dan Johnsson.)

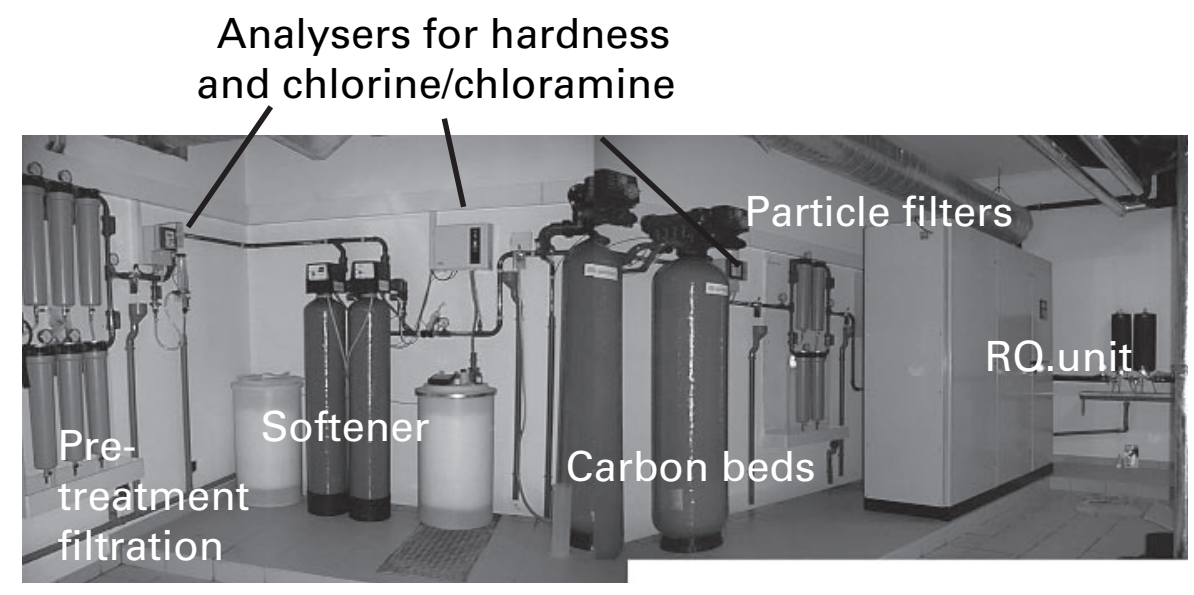

range of physicochemical factors such as temperature and particle size. It is important to be aware that there can be substantial daily variations in the levels of raw water, and regular monitoring of product water is highly desirable as chlorine is toxic to humans and chloramines react with body fluids to liberate oxygen-free radicals causing denaturing of haemoglobin cellular proteins and lipids by their inhibition of the hexose monophosphate pathway that produces NADPH. The standard concentration set for chlorine and chloramines is $0.1 \mathrm{mg} / \mathrm{l}$, whereas excessive exposure $(>3 \mathrm{mg} / \mathrm{l})$ is associated with the production of Heinz bodies, and a diminished response to recombinant human erythropoietin can occur between 0.1 and $0.2 \mathrm{mg} / 1$ [13-15].

An important element of the water treatment plant in the dialysis unit is the distribution loop which delivers the treated water from the treatment system to the proportionating unit. Routine disinfection of the entire water distribution system, including the connecting tubes and the dialysis monitor, is often neglected leading to the formation of a biofilm (fig. 2). A biofilm may also be present in the hydraulic circuit of the dialysis machine, where factors such as the use of liquid bicarbonate concentrate, the presence of areas of low flow or stagnation, or suboptimal sterilization procedures between uses play a role $[16,17]$. Once established, the removal of the biofilm is difficult, although recently, a new approach has been described [18].

Newer water treatment systems incorporate automated, nightly heat disinfection, which is helpful in preventing the formation of a biofilm [19]. However, such an approach cannot be used with polyvinyl chloride tubing and requires the use of more expensive and heat resistant materials such as cross-linked polyethylene, polyvinyli-

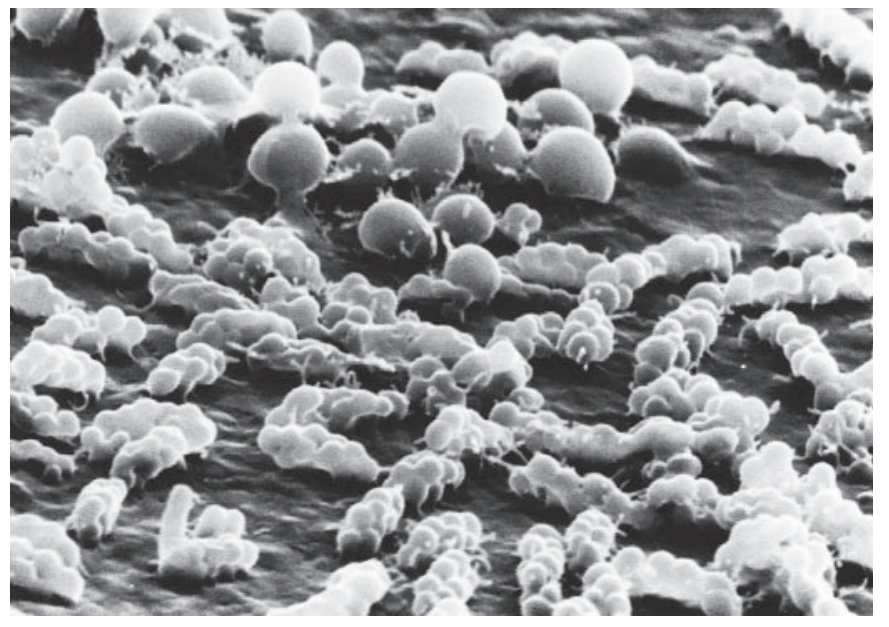

Fig. 2. Biofilm formed in a renal unit water distribution system. (Photograph by courtesy of Luc Marchal, Nancy, and Jean Printz, Colombes, France. Published with permission from Gambro Lundia AB, Lund, Sweden.)

dene fluoride, or stainless steel to prevent material degradation or fracture.

When a biofilm is present, it acts as a source of endotoxins, endotoxin fragments, muramyl peptides, and polysaccharides which are released into the water and have the potential to transfer across the dialysis membrane due to their molecular weights $(0.5-200 \mathrm{kDa})$. Consequently, low-flux (standard) dialysis does not necessarily translate into higher microbiological safety than high-flux dialysis or haemodiafiltration. Transfer can have immediate effects on the form of pyrogen reactions, and over a longer period, bacterial DNA fragments trigger Toll-like receptors on monocytes and in- 
duce cytokine production leading to an inflammatory response [20].

Extended exposure is linked to malnutrition and atherosclerosis [21] and is also important in determining the patient's response to epoetin [22].

\section{Water Quality Improvement}

The increasing recognition of the role that the quality of water plays in the improvement in outcomes for patients with end-stage renal disease has led to a tightening of the microbiological and endotoxin levels, compliance with which necessitates a rigorous quality control program. The essential elements of the quality control program used at dialysis centres managed by the Renal Research Institute are given below and include the following.

(1) Validation of the RO performance meets the chemical standards of the Association for the Advancement of Medical Instrumentation (AAMI), as well as the internally set microbiologic and endotoxin levels which are more rigorous than those specified by the AAMI standards and are in agreement with those of the European Pharmacopoeia.

(2) The installation of a hollow fibre polysulphone filter (Fibercor, Minntech Corp., Minneapolis, Minn., USA) to filter water entering the distribution loop.

(3) The installation of Diasafe filters (Fresenius Medical Care, Lexington, Mass., USA) on each dialysis machine, which has reduced the microbiologic contamination to $<20 \mathrm{CFU} / \mathrm{ml}$ and endotoxin levels to $<0.06 \mathrm{EU} /$ $\mathrm{ml}$.

(4) A weekly in-house monitoring of the distribution system using Millipore HPC paddles (red) and Associates of Cape Cod Limulus amebocyte lysate (LAL) single test vials at $0.06 \mathrm{EU} / \mathrm{ml}$ sensitivity. The elements of the distribution system thus monitored are the RO, the storage tank, post-pyrogen filter, midpoint of the loop, end of the loop, water feed to the bicarbonate mixer, and the deionization bypass system. Note that if limiting measurements to a monthly basis, samples must be drawn before disinfecting the system and not immediately afterwards.

(5) Quarterly measurements using the above for all dialysis machines. Regular validation of methods by samples sent to an outside laboratory.

(6) Routine disinfection of the RO loop at least monthly to ensure the specified standards are maintained. The dialysis machines must be included in this procedure so that the hose connecting the machine to the loop can also be disinfected.
(7) The RO should be cleaned and disinfected on at least a semiannual basis, or as needed. If any changes are made to the RO, such as membrane replacement or removal, the system is disinfected and samples are sent for chemical analysis to ensure that the water is still in compliance.

(8) Backup deionization systems must be included in the weekly microbiology monitoring program and monthly disinfection program, with appropriate action when a problem is detected. If, for example, the LAL test is positive at $0.06 \mathrm{EU} / \mathrm{ml}$ sensitivity but negative at $0.25 \mathrm{EU} / \mathrm{ml}$ sensitivity, a complete system disinfection is scheduled for the next weekend. However, if the LAL test is positive at $0.25 \mathrm{EU} / \mathrm{ml}$, the disinfection is performed the same night.

Rigorous attention to detail and design minimizes the potential for biofilm formation in new water treatment systems; elimination from older treatment plants and distribution networks is more problematic. When present, a strong bleach solution (1:10 to 1:4 concentration) may be recirculated through the distribution loop for a minimum of $2 \mathrm{~h}$ with no dwell time, and the process is repeated at least twice a week for 2 weeks and then reduced to weekly disinfections. The system must be continuously monitored, and as the bacterial and endotoxin levels are reduced, the time between disinfections can be extended until the system is able to remain within limits for 1 month. Once this occurs, the system disinfection may continue on a routine monthly basis.

\section{Evidence that Improved Water Quality Matters}

In the Renal Research Institute facilities, the water systems used are designed to achieve a water standard of $<20 \mathrm{CFU} / \mathrm{ml}$ for bacteria and $<0.06 \mathrm{EU} / \mathrm{ml}$ for endotoxin. In a retrospective analysis of data based on the median values calculated 3 months prior to the upgrading of the water treatment plant to provide the above quality water compared with those over a 6-month period following the upgrade based upon a sample of 342 patients is summarized in table 3 and indicates statistically significant increases in haemoglobin, albumin, ferritin, and transferrin saturation. The improvement in the water quality was also associated with a statistically significant decrease in C-reactive protein and creatinine.

In published clinical studies, the use of ultrapure dialysate (bacteria $<0.1 \mathrm{CFU} / \mathrm{ml}$ and endotoxin $<0.03 \mathrm{EU} /$ $\mathrm{ml}$ ) was associated with lower concentrations of inflammatory markers and acute phase reactants than those ob- 
Table 3. Influence of water treatment upgrade on patient biochemical and haematological parameters

\begin{tabular}{|c|c|c|c|}
\hline Parameter & Before upgrade & After upgrade & $\mathrm{p}$ value \\
\hline Monthly erythropoietin dosage ${ }^{\mathrm{a}}, \mathrm{U}$ & $85,800(70,000)$ & $82,500(731,500)$ & NS \\
\hline Four-monthly iron dosage ${ }^{\mathrm{a}}, \mathrm{mg}$ & $100(350)$ & $125(400)$ & NS \\
\hline Haemoglobin $^{\mathrm{b}}, \mathrm{g} / \mathrm{dl}$ & $10.9 \pm 1.4$ & $11.3 \pm 1.2$ & $<0.0001 *$ \\
\hline Erythropoietin/haematocrit ratio ${ }^{a}$ & $8,134(6,929)$ & $7,095(7,407)$ & 0.07 \\
\hline Albumin ${ }^{\mathrm{b}}, \mathrm{g} / \mathrm{dl}$ & $3.9 \pm 0.37$ & $3.94 \pm 0.36$ & $0.0002 *$ \\
\hline Ferritin $^{\mathrm{a}}, \mathrm{ng} / \mathrm{ml}$ & $251(389)$ & $355(429)$ & $<0.0001^{*}$ \\
\hline Transferrin saturation $^{\mathrm{a}}, \%$ & $26.0(14.5)$ & $30.5(17.3)$ & $<0.0001^{*}$ \\
\hline Creatinine $^{\mathrm{b}}, \mathrm{mg} / \mathrm{dl}$ & $10.6 \pm 3.3$ & $10.1 \pm 3.1$ & $<0.0001$ \\
\hline White cell count $\mathrm{t}^{\mathrm{b}}, \times 10^{3} / \mu \mathrm{l}$ & $6.5 \pm 2.1$ & $6.5 \pm 1.9$ & NS \\
\hline C-reactive protein ${ }^{\mathrm{a}}$ & $14.3(21.0)$ & $12.2(19.6)$ & $<0.0001^{*}$ \\
\hline
\end{tabular}

served with dialysate meeting current AAMI quality recommendations. The treatment of patients with ultrapure dialysate is reported to improve nutritional status, increase responsiveness to erythropoietin, slow the decline in residual renal function, lessen cardiovascular morbidity, and decrease the incidence of $\beta_{2}$-microglobulin amyloidosis. Moreover, observational studies suggest a link between clinical outcomes and dialysate purity [23-29].

\section{Composition of Dialysis Fluid}

Ideally, the composition of the dialysis fluid should be identical to that of plasma water of the healthy individual. Such an approach permits the removal of low molecular weight metabolite elevated as a consequence of renal failure and permits the normalization of electrolyte abnormalities associated with renal failure. Due to differences between individual patients and the trend towards treatment of elderly patients with comorbid conditions, the optimal level of each constituent remains a matter of continuing research.

\section{Dialysis Fluid Buffer}

Historically, single-patient proportionating systems for technical reason used acetate as the buffer, but with the availability of the new generation of dialysis machines, coupled with the side effects associated with acetate, it is rarely used today [30, 31]. The availability of a three-stream mixing for bicarbonate-buffered dialysis fluid has meant that bicarbonate has become the buffer of choice. It is well tolerated even by patients with cardiovascular problems, and its use is more physiological than acetate. Current proportionating systems also permit the variation of bicarbonate levels in discrete steps over the range of $20-40 \mathrm{mmol} / \mathrm{l}$, allowing individualization to achieve a midweek pre-dialysis serum bicarbonate concentration of $22 \mathrm{mmol} / \mathrm{l}$, as suggested by the National Kidney Foundation Kidney Disease Outcome Quality Initiative guidelines for maintenance dialysis patients in respect of acidosis.

\section{Electrolyte Composition}

\section{Sodium}

Opinion regarding the sodium concentration of dialysis fluid has been driven by the move towards shorter treatment times that require higher sodium concentrations for the prevention of intra-dialytic morbidity. However, such levels may exceed those of the patient, leading to a gain in sodium and increased thirst, arguing for a move towards individualized sodium levels for each patient. A study by Levin et al. [32] using a fixed dialysate $\mathrm{Na}^{+}$of $143 \mathrm{mmol} / 1$ showed that in $98 \%$ of 58 patients studied, the average pre-dialysis sodium concentrations were below the dialysate concentration leading to a gain in sodium during treatment. Furthermore, there was a significant relationship between the sodium gradient and mean arterial pressure before dialysis, an observation 
replicated in a more recent study [33]. Currently, the use of such an approach requires the knowledge of the patient's plasma $\mathrm{Na}^{+}$levels at the start of dialysis, and such measurement may not be readily available at the bedside.

Many dialysis machines offer the potential to vary sodium in the dialysis fluid during treatment (sodium profiling). In sodium profiling, the sodium concentration in the dialysis fluid follows a time-dependent profile over the course of a haemodialysis session. The main aim of this manipulation is to avoid osmotic disequilibrium by keeping plasma osmolality in the physiological range. Further advantages of sodium profiling are a reduction in the incidence of muscle cramps, improved sodium removal, and improved vascular stability. Many different profiles have been used by various investigators, but there is a lack of consensus as to which is the most appropriate; furthermore, there may also be a risk of sodium accumulation with profiling resulting in increased thirst and an increase in interdialytic weight gain due to suppression of the thirst by fluid intake leading to hypertension [34].

\section{Potassium}

Haemodialysis patients are subject to a disturbed potassium homeostasis and are frequently hyperkalaemic. The removal of potassium during dialysis is achieved via diffusion, setting the level in the dialysis fluid lower than in the plasma water. The amount required to be removed during treatment varies between 50 and $100 \mathrm{mmol} / \mathrm{l} \mathrm{de}$ pending on patient dietary compliance. The primary factors influencing removal are pre-dialysis plasma concentration, dialysis fluid potassium concentration, dialyzer efficiency or clearance, and treatment time. For stable dialysis patients, a dialysate potassium level of $2 \mathrm{mmol} / \mathrm{l}$ maintains the plasma levels below $6 \mathrm{mmol} / \mathrm{l}$ and avoids post-dialysis hypokalaemia. Patients with cardiac disease and arrythmias may need higher potassium levels in the dialysis fluid (3-3.5 mmol/l), coupled with frequent monitoring of plasma potassium levels as a fall in serum potassium predisposes the patient to an increased QT dispersion which may be ameliorated by potassium profiling $[35,36]$.

\section{Calcium}

The total plasma calcium concentrations in a healthy adult are maintained physiologically within a narrow range $(2-2.6 \mathrm{mmol} / \mathrm{l})$. Calcium is present in extracellular fluid in three different forms: protein bound, complexed, and ionized. A wide range of calcium levels exists in pa- tients with renal failure depending upon the use of vitamin D, calcitriol, calcium salts (used as phosphate binders) and the intra-dialytic calcium balance. Historically, dialysis fluid calcium concentrations were set close to those of plasma (1.1-1.4 mmol/l); however, recognition of the role that hypocalcaemia plays in the genesis of hyperparathyroidism and renal osteodystrophy has led to the use of higher concentrations of calcium (approximately $1.75 \mathrm{mmol} / \mathrm{l})$, as this results in a positive intradialytic calcium balance. Today, with the increased use of calcium-based phosphate binders and calcitriol, the level has been reduced to $1.25-1.50 \mathrm{mmol} / \mathrm{l}$. At the lower end of this range, a potential exists (in the presence of pharmacological non-compliance) for a negative calcium balance which may worsen hyperparathyroidism in the patient [37]. Low levels of calcium may also increase the risk of arrythmias, and in view of these issues, no single calcium concentration is appropriate for all patients, although a level of $1.5 \mathrm{mmol} / \mathrm{l}$ would be suitable for many.

\section{Magnesium}

Magnesium has an important role in many functions of the body. Dietary intake of magnesium is adsorbed via the gut and excreted in the urine. Thus, dialysis patients have elevated levels of plasma magnesium, the normalization of which is brought about by diffusive and convective removal across the dialyser membrane into the dialysis fluid. Most commercially manufactured concentrates contain magnesium concentrations ranging from 0.25 to $0.75 \mathrm{mmol} / \mathrm{l}$. High concentrations may suppress the production of parathyroid hormone (PTH). Low concentrations improve bone mineralization and resolve bone pain, but may increase PTH levels and cause cramps during dialysis. Levels around $0.5 \mathrm{mmol} / \mathrm{l}$ are most widely used.

\section{Chloride}

The chloride concentration of commercially produced dialysis fluids varies between 98 and $112 \mathrm{mmol} / \mathrm{l}$ and is governed by the presence of electrolytes such as sodium, potassium, calcium, and magnesium, as they are present in the dialysis fluid as chloride salts.

\section{Glucose}

Contemporary dialysis fluids can be glucose-free, isoglycaemic $(100 \mathrm{mg} / \mathrm{dl})$ or hyperglycaemic $(200 \mathrm{mg} / \mathrm{dl})$. The use of glucose-free dialysis fluid is associated with significant glucose loss during treatment with a risk of hypoglycaemia and should be avoided. A glucose concentration of $100 \mathrm{mg} / \mathrm{dl}$ seems reasonable for the majority of 
patients, and $200 \mathrm{mg} / \mathrm{dl}$ should be used for those patients in whom the nutritional value of supplementation is a high priority; such levels may also be helpful in ameliorating post-dialysis fatigue and headache [38].

\section{Conclusion}

The avoidance of complications arising from water contaminants, be it chemical or microbiologic, requires a constant and vigorous attention to water quality to ensure compliance. Water standards in respect of micro- biological contaminants are currently under review, and tighter levels are likely. In respect of electrolyte and buffer composition of the dialysis fluid, the formulation is gradually moving from a fixed, standard composition to individualization of both electrolyte and buffer composition, not only during the dialysis session, but also within the same session (profiling) to provide patients with optimal treatment coupled with a high degree of treatment tolerance.

\section{References}

1 Alfrey AC, LeGendre GR, Kaehny WD: The dialysis encephalopathy syndrome. Possible aluminum intoxication. N Engl J Med 1976; 294:184-188.

2 Parkinson IS, Ward MK, Kerr DN: Dialysis encephalopathy, bone disease and anaemia: the aluminum intoxication syndrome during regular haemodialysis. J Clin Pathol 1981;34: 1285-1294.

3 Monograph 1167 (1997, corrected 2000, republished 2001). Haemodialysis Solutions, Concentrated, Water for Diluting. European Pharmacopoeia Supplement. Strasbourg, Council of Europe Publishers, 2001.

4 Association for the Advancement of Medical Instrumentation (AAMI): Water Treatment Equipment for Hemodialysis Applications (ANSI/AAMI RD62:2001). American National Standard. Arlington, AAMI, 2001.

-5 ERA-EDTA European best practice guidelines for haemodialysis. 4. Dialysis fluid purity. Nephrol Dial Transplant 2002; 17(suppl 7):4562.

-6 O'Brien AA, Moore DP, Keogh JA: Acute epidemic aluminium osteomalacia secondary to water supply contamination. Ir J Med Sci 1990;159:71-73.

7 Pizzarelli F, Cerrai T, Biagini M, Malaguti M, Bargagna R: Dialysis water treatment systems and monitoring in Italy: results of a national survey. J Nephrol 2004; 17:565-569.

-8 Laurence RA, Lapierre ST: Related quality of hemodialysis water: a 7-year multicenter study. Am J Kidney Dis 1995;25:738-750.

-9 Vorbeck-Meister I, Sommer R, Vorbeck F, Horl WH: Quality of water used for haemodialysis: bacteriological and chemical parameters. Nephrol Dial Transplant 1999;14:666675.

10 Zunino P, Beltran L, Zunino L, Mendez H, Percovich V, Rocca R, Antonelli B: Microbiological quality of hemodialysis water in a threeyear multicenter study in Uruguay. J Nephrol 2002; 15:374-379.

Water Quality and Haemodialysis Fluid Composition
1 Cannata-Andia JB: Reconsidering the importance of long-term low-level aluminum exposure in renal failure patients. Semin Dial 2001; 14:5-7.

12 Fernandez-Martin JL, Canteros A, Alles A, Massari P, Cannata-Andia J: Aluminum exposure in chronic renal failure in Iberoamerica at the end of the1990s: overview and perspectives. Am J Med Sci 2000;320:96-99.

13 Caterson RJ, Savdie E, Raik E, Coutts D, Mahony JF: Heinz-body haemolysis in haemodialysed patients caused by chloramines in Sydney tap water. Med J Aust 1982;2:367-368.

14 Fluck S, McKane W, Cairns T, Fairchild V, Lawrence A, Lee J, Murray D, Polpitiye M, Palmer A, Taube D: Chloramine-induced haemolysis presenting as erythropoietin resistance. Nephrol Dial Transplant 1999;14: 1687-1691.

15 Pyo HJ, Kwon YJ, Wee KS, Kwon SY, Lee CH, Kim S, Lee JS, Cho SH, Cha CW: An outbreak of Heinz body positive hemolytic anemia in chronic hemodialysis patients. Korean J Intern Med 1993;8:93-98.

16 Bland LA, Ridgeway MR, Aguero SM, Carson LA, Favero MS: Potential bacteriologic and endotoxin hazards associated with liquid bicarbonate concentrate. ASAIO Trans 1987;33: 542-545.

17 Cappelli G, Sereni L, Scialoja MG, Morselli M, Perrone S, Ciuffreda A, Bellesia M, Inguaggiato P, Albertazzi A, Tetta C: Effects of biofilm formation on haemodialysis monitor disinfection. Nephrol Dial Transplant 2003;18:21052111.

18 Marion K, Pasmore M, Freney J, Delawari E, Renaud F, Costerton JW, Traeger J: A new procedure allowing the complete removal and prevention of hemodialysis biofilms. Blood Purif 2005;23:339-348.

19 Smeets E, Kooman J, van der Sande F, Stobberingh E, Frederik P, Claessens P, Grave W, Schot A, Leunissen K: Prevention of biofilm formation in dialysis water treatment systems. Kidney Int 2003;63:1574-1576.
20 Schindler R, Beck W, Deppisch R, Aussieker M, Wilde A, Gohl H, Frei U: Short bacterial DNA fragments: detection in dialysate and induction of cytokines. J Am Soc Nephrol 2004; 15:3207-3214.

21 Pecoits-Filho R, Lindholm B, Stenvinkel P: The malnutrition, inflammation, and atherosclerosis (MIA) syndrome - The heart of the matter. Nephrol Dial Transplant 2002;17(suppl 11):28-31.

22 Richardson D: Clinical factors influencing sensitivity and response to epoetin. Nephrol Dial Transplant 2002;17(suppl 1):53-59.

-23 Arizono K, Nomura K, Motoyama T, Matsushita Y, Matsuoka K, Miyazu R, Takeshita H, Fukui H: Use of ultrapure dialysate in reduction of chronic inflammation during hemodialysis. Blood Purif 2004;22(suppl 2):26-29.

24 Schiffl H, Lang SM, Fischer R: Ultrapure dialysis fluid slows loss of residual renal function in new dialysis patients. Nephrol Dial Transplant 2002;17:1814-1818.

25 Lederer SR, Schiffl H: Ultrapure dialysis fluid lowers the cardiovascular morbidity in patients on maintenance hemodialysis by reducing continuous microinflammation. Nephron 2002;91:452-455.

- 26 Hsu PY, Lin CL, Yu CC, Chien CC, Hsiau TG, Sun TH, Huang LM, Yang CW: Ultrapure dialysate improves iron utilization and erythropoietin response in chronic hemodialysis patients - A prospective cross-over study. J Nephrol 2004; 17:693-700.

27 Lonnemann G, Koch KM: Beta(2)-microglobulin amyloidosis: effects of ultrapure dialysate and type of dialyzer membrane. J Am Soc Nephrol 2002;13(suppl 1):S72-S77.

-28 Tielemans C, Husson C, Schurmans T, Gastaldello K, Madhoun P, Delville JP, Marchant A, Goldman M, Vanherweghem JL: Effects of ultrapure and non-sterile dialysate on the inflammatory response during in vitro hemodialysis. Kidney Int 1996;49:236-243. 
29 Rahmati MA, Homel P, Hoenich NA, Levin R, Kaysen GA, Levin NW: The role of improved water quality on inflammatory markers in patients undergoing regular dialysis. Int $\mathrm{J}$ Artif Organs 2004;27:723-727.

30 Malberti F, Surian M, Colussi G, Minetti L: The influence of dialysis fluid composition on dialysis tolerance. Nephrol Dial Transplant 1987;2:93-98.

31 Fantuzzi S, Caico S, Amatruda O, Cervini P, Abu-Turky H, Baratelli L, Donati D, Gastaldi L: Hemodialysis-associated cardiac arrhythmias: a lower risk with bicarbonate? Nephron 1991;58:196-200.
2 Levin NW, Zhu F, Keen M: Interdialytic weight gain and dry weight. Blood Purif 2001; 19:217-221.

33 De Paula FM, Peixoto AJ, Pinto LV, Dorigo D, Patricio PJ, Santos SF: Clinical consequences of an individualized dialysate sodium prescription in hemodialysis patients. Kidney Int 2004;66:1232-1238.

-34 Stiller S, Bonnie-Schorn E, Grassmann A, Uhlenbusch-Korwer I, Mann H: A critical review of sodium profiling for hemodialysis. Semin Dial 2001; 14:337-347.

35 Cupisti A, Galetta F, Caprioli R, Morelli E, Tintori GC, Franzoni F, Lippi A, Meola M, Rindi P, Barsotti G: Potassium removal increases the QTc interval dispersion during hemodialysis. Nephron 1999;82:122-126.
36 Santoro A, Mancini E, Gaggi R, Cavalcanti S, Severi S, Cagnoli L, Badiali F, Perrone B, London G, Fessy H, Mercadal L, Grandi F: Electrophysiological response to dialysis: the role of dialysate potassium content and profiling. Contrib Nephrol 2005;149:295-305.

37 Fabrizi F, Bacchini G, Di Filippo S, Pontoriero G, Locatelli F: Intradialytic calcium balances with different calcium dialysate levels. Effects on cardiovascular stability and parathyroid function. Nephron 1996;72:530-535.

38 Raju SF, White AR, Barnes TT, Smith PP, Kirchner KA: Improvement in disequilibrium symptoms during dialysis with low glucose dialyzate. Clin Nephrol 1982;18:126-129. 